\title{
A (RE)CONSTRUÇÃO DE REFERENTES EM PERFIL FAKE DO FACEBOOK: UMA ANÁLISE COGNITIVO-DISCURSIVA
}

Ananda Veloso Amorim OLIVEIRA*

Silvana Maria Calixto de LIMA**

RESUMO

A partir de uma concepção cognitivo-discursiva do processo de recategorização, este artigo analisa expressões referenciais recategorizadoras de três postagens do perfil fake Irmã Zuleide. Tomamos como modelo de análise a proposta de Lima e Feltes (2013), cuja base está assentada na Teoria dos Modelos Cognitivos Idealizados (LAKOFF, 1987). A análise engloba a identificação e descrição dos modelos cognitivos evocados a partir das pistas linguísticas. Os resultados corroboram a tese de Lima (2009) de que, na atividade discursiva, alguns referentes só podem ser homologados se recorrermos ao nível das estruturas e do funcionamento cognitivo, necessitando, portanto, de ancoragem em modelos cognitivos.

PalaVRas-chaVE: Referenciação, Recategorização, Modelos cognitivos idealizados, Facebook.

\section{INTRODUÇÃO}

Este trabalho tem como objetivo analisar expressões referenciais recategorizadoras presentes em três publicações de

* Técnica em Assuntos Educacionais, do Instituto Federal de Educação, Ciência e Tecnologia do Maranhão (IFMA), Câmpus Coelho Neto, Coelho Neto, MA, Brasil. E-mail: ananda_amorim@hotmail.com.

** Professora Doutora em Linguística da Universidade Estadual do Piauí (UESPI), do Mestrado Profissional em Letras (UESPI) e do Mestrado Acadêmico em Letras da Universidade Federal do Piauí (UFPI), Teresina, PI, Brasil. E-mail: scalixto2003@yahoo.com.br. 
um perfil fake $e^{1}$ do Facebook (Irmã Zuleide), com base no modelo analítico proposto por Lima e Feltes (2013). Tal modelo é delineado a partir de uma interface entre a Linguística de Texto (doravante LT) e a Linguística Cognitiva (adiante LC), consolidada pela Teoria dos Modelos Cognitivos Idealizados (ao longo do texto MCIs), de Lakoff (1987), lançando-se mão, particularmente, dos modelos cognitivos proposicionais (frames e scripts) e dos modelos cognitivos metafóricos e metonímicos.

Acrescentamos que a proposta de análise desenvolvida tem como base a hipótese defendida em Lima (2009) de que, no processamento textual-discursivo, os referentes nem sempre aparecem materializados por meio de expressões linguísticas. Em outros termos, isso significa que, em muitos casos, os referentes não são homologados na própria materialidade textual, mas a partir de inferências e processos cognitivos mais complexos, ainda que (re)construídos por meio de pistas linguísticas, à luz dos postulados da Referenciação também assumidos neste estudo, como detalhamos adiante.

A constituição do corpus de análise se deveu à popularidade do perfil "Irmã Zuleide" na rede social Facebook, bem como pelo trabalho criativo desenvolvido com a linguagem em uso nesse perfil. Foi definitivo também o fato de que as postagens do fake Irmã Zuleide apresentam, com significativa frequência, ocorrências do processo de recategorização, objeto de pesquisa para o qual converge o nosso interesse neste artigo.

Na primeira parte deste trabalho, apresentamos os pressupostos teóricos que fundamentam as análises do corpus constituído para investigação, fazendo uma abordagem da perspectiva da Referenciação, com foco mais específico no processo de recategorização, bem como uma apresentação, em linhas gerais, da Teoria dos Modelos Cognitivos Idealizados. Na segunda e última parte, trazemos a análise propriamente dita, momento em que reunimos indícios que validam a tese de Lima (2009) de que, na atividade de construção de sentidos do texto, alguns referentes só podem ser homologados se recorrermos ao nível das estruturas e do funcionamento cognitivo, necessitando, portanto, de ancoragem em MCIs para que sejam (re) construídos no processamento textual-discursivo. 
2 REFERENCIAÇÃO: PARA ALÉM DA MATERIALIDADE TEXTUALDISCURSIVA E POR UMA INTERFACE COM A LINGUÍSTICA COGNITIVA

\subsection{BREVE CONTEXTO E DEFINIÇÃO DA ABORDAGEM DA REFERENCIAÇÃO}

Nos últimos anos do século XX, a perspectiva da Referenciação (MONDADA; DUBOIS, 1995) surge com o propósito de redimensionar a visão clássica de referência enquanto propriedade das palavras em categorizar as coisas do mundo, passando a ser compreendida como um processo que se concretiza na atividade discursiva. Essa moderna abordagem da referência emerge no quadro dos teóricos sociocognitivistas ${ }^{2}$, cujos trabalhos têm influenciado sobremaneira os estudos da LT no que se refere ao modo de investigar os processos de construção de sentidos do texto, considerando tanto os aspectos sociais como os cognitivos, numa clara ruptura com os pressupostos do cognitivismo clássico de uma separação radical entre os fenômenos mentais e sociais.

Nesse contexto, conforme explicam Koch e Cunha-Lima (2004, p. 295), o entendimento passa a ser o de que:

O sentido das palavras e textos não lhes é imanente e não é depreensível numa atividade de cálculo com regras rígidas previamente estabelecidas. O sentido é necessariamente situado histórica e socialmente e é, também, plástico, no sentido de que, em todos os níveis da linguagem, existe uma negociação entre os interactantes para o estabelecimento desse sentido. A linguagem não traz os objetos do mundo para dentro do discurso e sim trata esses objetos de diversas maneiras, a fim de atender a diversos propósitos comunicativos: passa-se a falar, então, em objetos-de-discurso.

Depreendemos da afirmação das autoras que a visão clássica da referência perdeu espaço para uma concepção que valoriza tanto o aspecto social da linguagem quanto o cognitivo. De fato, a construção do referente é o resultado de uma negociação entre os interactantes, processo que inclui os conhecimentos compartilhados e situados historicamente, o que garante ao referente estatuto de objeto de discurso. Em outros termos, "os objetos de discurso não podem ser compreendidos como expressões referenciais que mantêm uma relação de espelhamento com 
os objetos do mundo ou até mesmo com a representação cognitiva que deles se venha a ter, pois somente têm razão de ser no discurso" (LIMA; FELTES, 2013, p. 33).

É fato, ainda, que a abordagem da Referenciação atribui às expressões referenciais função diversa da função de referir. Conforme assevera Koch (2011, p. 106), "como multifuncionais que são elas contribuem para elaborar o sentido, indicando pontos de vista, assinalando direções argumentativas, sinalizando dificuldades de acesso ao referente e recategorizando os objetos presentes na memória discursiva".

Compreendida a construção da referência nos termos apresentados, assumimos, neste trabalho, a concepção sociocognitiva de texto, pela qual se tem o entendimento de que o processo de construção dos sentidos não se restringe à materialidade textual. A respeito disso, Cavalcante $\mathrm{e}$ Custódio Filho (2010, p. 62) chamam a atenção para o fato de "o caráter do texto, no estágio atual dos estudos em LT, falar em favor de um objeto dinâmico, multifacetado, resultante de uma atividade linguísticosociocognitiva, na qual se incluem parâmetros discursivos". Ademais, concordamos com os referidos autores quando assumem a importância de se analisar não somente os sentidos e conhecimentos construídos na produção e/ou recepção dos textos, mas também a de atentar para os contextos sócio-históricos, pois, conforme eles dizem, “[...] o cotexto, embora fundamental como ponto de partida, não garante a completude dos sentidos" (CAVALCANTE; CUSTÓDIO FILHO, 2010, p. 60).

Desse modo, tendo como foco essa completude dos sentidos, é que propomos, neste estudo, uma interface com a $\mathrm{LC}^{3}$, a fim de não nos limitarmos ao cotexto e buscarmos explicações mais abrangentes que deem conta da análise das ocorrências de recategorização constituintes do corpus deste trabalho. Antes de tratarmos especificamente da Teoria dos Modelos Cognitivos Idealizados, ponte que viabiliza a construção dessa interface, julgamos necessário definir a concepção de recategorização assumida, tema da próxima subseção.

\subsection{O PROCESSO DE RECATEGORIZAÇÃO}

Na literatura, o estudo pioneiro da recategorização é creditado a Apothéloz e Reichler-Béguelin (1995). Esses autores definem a 
recategorização como uma estratégia de designação, na atividade discursiva, pela qual os referentes podem ser remodulados, sistematizando também uma proposta de classificação das recategorizações lexicais, porém, limitados ainda a uma abordagem textual-discursiva desse fenômeno.

A partir do trabalho seminal dos autores, Lima (2009) propõe um redimensionamento da concepção de recategorização, nos termos seguintes, reivindicando uma abordagem cognitivo-discursiva para esse processo de Referenciação.

i) a recategorização nem sempre pode ser reconstruída diretamente no nível textual-discursivo, não se configurando apenas pela remissão ou retomada de itens lexicais; ii) em se admitindo (i), a recategorização deve, em alguns casos, ser (re) construída pela evocação de elementos radicados num nível cognitivo, mas sempre sinalizados por pistas linguísticas, para evitar-se extrapolações interpretativas; iii) em decorrência de (ii), a recategorização pode ter diferentes graus de explicitude e implicar, necessariamente, processos inferenciais. (LIMA, 2009, p. 57)

Reportamo-nos, pois, a essa concepção para subsidiar nossa análise acerca das expressões referenciais recategorizadoras e reafirmamos o trabalho com a perspectiva cognitivo-discursiva. Dessa maneira, podemos contemplar um nível mais profundo que o textualdiscursivo, porém, sempre orientado pelas pistas linguísticas.

Para tanto, recorremos a uma interface com a LC, particularmente com a Semântica Cognitiva experiencialista ${ }^{4}$, da qual utilizamos como aporte teórico a Teoria dos Modelos Cognitivos Idealizados (TMCIs) proposta por Lakoff (1987). Na construção de seu modelo teórico, o autor defende a tese da organização do conhecimento por meio de estruturas as quais ele denomina de Modelos Cognitivos Idealizados (MCI). Dessa forma, ele define um MCI "como um todo estruturado complexo, uma gestalt”. (LAKOFF, 1987, p. 68), em que concorrem quatro tipos de princípios estruturadores: i) estrutura proposicional; ii) estrutura de esquemas de imagens; iii) mapeamentos metafóricos e iv) mapeamentos metonímicos. Assim, os MCIs são estruturas cognitivas que constituem domínios nos quais os conceitos adquirem significação, "sendo usados 
para compreender o mundo e para criar teorias sobre o mundo" (LAKOFF, 1987, p. 134). Como acrescentam Lima e Feltes (2013), os MCIs emergem como conhecimentos compartilhados e não como construções meramente subjetivas, além de não serem representações da realidade, mas construções idealizadas, como o próprio nome já sugere.

Na configuração da TMCIs, Lakoff (1987) apresenta cinco tipos básicos de modelos cognitivos, a saber: i) proposicionais; ii) de esquemas de imagens; iii) metafóricos; iv) metonímicos e v) simbólicos. Do arcabouço dessa teoria, seguindo Lima e Feltes (2013), contemplamos apenas os modelos cognitivos proposicionais (scripts e (rames $)^{5}$, metafóricos e metonímicos, dos quais passamos a fazer uma breve caracterização na sequência.

O modelo proposicional do tipo script, com base em Lakoff (1987) e na revisão de sua obra em Feltes (2007), pode ser definido como "uma cadeia de inferências pré-organizadas, numa sequência de conceptualizações, relativa a uma situação de rotina específica (ou evento)" (LIMA; FELTES, 2013, p. 42).

Para efeito de exemplificação, mencionamos o clássico script de restaurante proposto por Schank e Kass (1988) e retomado em Feltes (2007), Lima (2009) e Lima e Feltes (2013), por meio do qual é possível capturar o conhecimento de alguém sobre a sequência dos eventos que integram a situação de sair para comer em um restaurante:

SCRIPT DO RESTAURANTE: i) ir ao restaurante; ii) sentar; iii) pedir uma refeição ao garçom; iv) receber a refeição do garçom; v) comer; vi) pagar a conta; vii) sair do restaurante.

Já os frames, como explica Feltes (2007, p. 135), "são estruturas com o papel de representar entidades conceptuais, [...] as quais 'emolduram' uma grande quantidade de conhecimentos sobre um determinado conceito". Como exemplo desse tipo de modelo cognitivo, Lakoff e Johnson (1999) citam a palavra "garçom", que é definida em relação ao frame de restaurante.

Em se tratando dos modelos metafóricos, esclarecemos que estes são descritos a partir da abordagem da metáfora conceitual em Lakoff e Johnson (1980), que passou a ser conhecida como Teoria da Metáfora Conceitual (TMC). Nesse modelo teórico, os autores postulam a intensa 
recorrência de metáforas tanto na linguagem como no pensamento e na ação, ou seja, "nosso sistema conceitual comum, em termos do qual pensamos e agimos, é de natureza fundamentalmente metafórica" (LAKOFF; JOHNSON, 1980, p. 3).

Nesse contexto, Lakoff (1987) apresenta a seguinte descrição dos modelos cognitivos metafóricos:

Um mapeamento metafórico envolve um domínio-fonte e um domínio-alvo. O domínio fonte é presumido como estruturado por um modelo proposicional ou de esquema de imagens. O mapeamento é tipicamente parcial; mapeia a estrutura do MCI no domínio fonte para a estrutura correspondente no domínio alvo. [...] os domínios fonte e alvo são representados estruturalmente pelo esquema do CONTAINER, e o mapeamento é representado pelo esquema ORIGEM-PERCURSO-META. (LAKOFF, 1987, p. 288)

Para ilustrar esse tipo de modelo, apresentamos a metáfora conceitual AMOR É UMA VIAGEM, presente em ocorrências da língua do tipo Estamos numa encruzilhada e Esta relação está afundando (LAKOFF; JOHNSON, 1980, p. 24). Na descrição dessa metáfora, temos uma projeção do domínio-fonte VIAGEM para o domínio-alvo AMOR. Nesse caso, Lakoff (1993) explica que há uma transferência de muitos aspectos do domínio experiencial de viagem para o domínio do amor, permitindo o estabelecimento de correspondências, tais como: OS AMANTES CORRESPONDEM AOS VIAJANTES, O RELACIONAMENTO AMOROSO CORRESPONDE A UM VEÍCULO e AS DIFICULDADES NO RELACIONAMENTO CORRESPONDEM AOS IMPEDIMENTOS NA VIAGEM.

Os modelos metonímicos, por sua vez, decorrem de um deslocamento de significado no qual uma expressão é utilizada para se referir a outra, com a qual estabelece relação de contiguidade e podem ser assim esquematizados, como apresenta Lakoff (1987):

- Há um conceito "alvo" A a ser compreendido para algum propósito, em algum contexto;

- Há uma estrutura conceitual contendo tanto A como um outro conceito $\mathbf{B}$; 
- B ou é parte de A ou está intimamente associado com ele nessa estrutura conceitual. Tipicamente, a escolha de B determinará especificamente A, dentro dessa estrutura conceitual;

- Comparado com A, B é ou mais fácil de compreender, ou mais fácil de lembrar, ou mais fácil de reconhecer, ou mais imediatamente utilizável para a um dado propósito num determinado contexto;

- Um modelo metonímico é um modelo de como A e B estão relacionados numa estrutura conceitual; a relação é especificada por uma função de B para A. (LAKOFF, 1987, p. 84)

Como ilustração do modelo metonímico, citamos o exemplo seguinte de Lakoff (1987, p. 77), em que a expressão "o sanduíche de presunto" é licenciada por uma metonímia conceitual, pois o item ordenado pelo consumidor (sanduíche de presunto) está pelo consumidor, com o esclarecimento ainda de que ambas as entidades pertencem ao mesmo modelo cognitivo de RESTAURANTE.

1. O sanduíche de presunto acabou de derramar toda a cerveja sobre ele.

Por último, consideramos salutar maiores esclarecimentos sobre a designação expressões referenciais recategorizadoras delimitada em Lima e Feltes (2013). As autoras defendem que os referentes nem sempre estão lexicalizados ou materializados na superfície do texto, estando a sua reconstrução sujeita à recorrência ao nível das estruturas e do funcionamento cognitivo, como ilustra o exemplo abaixo:

2. italofabris@programapanico Vovó, porque você não se candidata à presidência? já [sic!] tem um vampiro, só está faltando a múmia!! About 16 hours ago via web in reply to programapanico Retweeted by programapanico and 100+others. (http://twitter.com/PROGRAMAPANICO. Acesso em: 25 fev. 2010) (citado por LIMA; FELTES, 2013, p. 35).

De acordo com Lima e Feltes (2013), o referente "José Serra", recategorizado no exemplo, supra pela expressão referencial recategorizadora "um vampiro", é (re) construído no discurso através 
da evocação de elementos radicados num nível cognitivo, mas sempre guiados por pistas linguísticas. As autoras acrescentam que, nesta recategorização, o enunciador conta com o conhecimento compartilhado dos interlocutores, que ligam o nome de José Serra à Operação Vampiro, bem como associam o referente à imagem de um vampiro, veiculada na mídia por certo tempo. Nesse sentido, podemos constatar que os processos inferenciais são requisitados para a reconstrução do referente recategorizado como um vampiro.

De forma ampliada, as autoras defendem que somente numa perspectiva cognitivo-discursiva o processo de reconstrução de alguns referentes pode ser compreendido, suscitando, dessa forma, a importância de se investigar o fenômeno da recategorização em interface com a LC, como assim empreendemos neste artigo.

\section{EXPRESSÕES REFERENCIAIS RECATEGORIZADORAS EM POSTAGENS DE PERFIL FAKE DO FACEBOOK}

Feitas as considerações acerca do referencial teórico, reiteramos o nosso propósito de analisar as ocorrências de expressões referenciais recategorizadoras ancoradas nos MCIs, mas conscientes de que, por se tratarem de modelos idealizados, as análises e apreensões de sentido aqui realizadas não se esgotam e nem devem ser tomadas como prototípicas, visto que compreendemos que ao processo de interpretação subjazem os conhecimentos compartilhados, experiências vividas, valores, dentre outros.

Dessa forma, atentamos para Lima e Feltes (2013, p. 47) quando esclarecem que análises como as realizadas neste estudo são simulações e, por essa razão, "devem ser entendidas como apenas plausíveis, segundo um modelo teórico de interface, e tomadas como hipóteses de trabalho para uma investigação empírica".

Analisamos três postagens de um perfil fake do Facebook (Irmã Zuleide) segundo o percurso metodológico e de análise aplicado em Lima e Feltes (2013), a saber: i) identificação e descrição dos modelos proposicionais (frame e script), evocados a partir de pistas linguísticas; ii) identificação e descrição dos modelos metafóricos e metonímicos 
estruturados dentro dos frames e scripts identificados, sempre guiados pelas pistas das expressões referenciais recategorizadoras.

Na postagem (1) seguinte, o conjunto de expressões linguísticas iniciais, ativa o frame JOGO, do qual são constitutivos os elementos JOGADORES, VENCEDOR E MUDANÇA DE NÍVEL, dentre outros. Relacionado a esse frame, bem como aos seus elementos constitutivos, temos o script PARTIDA DE JOGO, que envolve uma sequência: (i) escolha de personagens; (ii) utilização de códigos; (iii) cumprimento de missões, (iv) mudanças de nível e (v) alcance de estrelas, mas não necessariamente nessa ordem.

Figura 1 - POSTAGEM 1

Tava jogando GTA com minha filha Clotilde então ela vestiu a camisa do Corinthians e do nada apareceu 6 estrelas de polícia, entendi nada

Fonte: Captura em Print Screen (Disponível em:< https://www.facebook.com/ ZuleideJequiti?fref=ts $>$ Acesso em: 01 jul. 2013).

Entendemos que o referido script colabora para a visualização da importância que é dada à mudança de nível em um jogo, sobretudo no Grand Theft Auto (GTA), criado pela produtora escocesa Rockstar Games. O contexto do jogo se dá a partir da história de Carl Johnson (CJ), que regressa a casa depois da sua mãe ter sido assassinada, mas, por ter sido culpado de homicídio, viaja para fugir da polícia, e é justamente neste itinerário que surgem as missões, as mudanças de nível e alcance de estrelas por parte dos jogadores.

Esclarecemos que o alcance de 6 estrelas, evocado dentro dos MCIs proposicionais (frame e script), no âmbito do jogo, está associado ao nível de procurado pela polícia, ou seja, representa o nível máximo e também mais difícil do jogo, uma vez que para atingi-lo subentende-se que o jogador cometeu uma série de crimes mais violentos dentro do jogo, como homicídios, e não roubos de carros, por exemplo.

$\mathrm{Na}$ postagem em análise, o referente "torcida do Corinthians" é recategorizado metonimicamente pela expressão "a camisa do 
Corinthians", visto que ocorreu um deslocamento de significado numa relação PARTE (Vestimenta: camisa do time) PELO TODO (Usuário: Torcedor do Corinthians). O referente "violência extrema", por sua vez, é metonimicamente recategorizado pela expressão " 6 estrelas da polícia", tendo em vista que quando o jogador atinge as 6 estrelas consegue a pontuação máxima no jogo, o que implica ter cometido vários crimes, bem como o aumento da perseguição por parte da polícia (o nível de procurado). Nesse contexto, a projeção metonímica se dá numa relação de CAUSA (praticar atos extremamente violentos) pelo EFEITO (atingir o nível máximo do jogo), confirmada pela expressão "6 estrelas de polícia".

Com base no exposto, verificamos que a construção dos referentes "violência extrema" e "torcida do Corinthians" não se homologa na superfície do texto, requerendo, pois, para sua apreensão, ancoragem nos MCIs evocados pelas pistas linguísticas e também através do conhecimento compartilhado entre os interlocutores. Sobre isso, é importante destacar a repercussão das atitudes violentas de torcedores do Corinthians na mídia e o conhecimento do objetivo, etapas e conteúdo do jogo GTA na apreensão do sentido e propósito cômicoirônico da publicação.

Figura 2 - POSTAGEM 2

\footnotetext{
$\theta$

Irmá Zuleide

16 de maio 8

Tá todo mundo dizendo que o Timão foi derrotado, não acredito que o Pumba bateu nele, esses desenhos da Disney só ensinam violência!!

Curtir - Comentar - Compartilhar

Fonte: Captura em Print Screen. (Disponível em: < https:/www.facebook.com/ ZuleideJequiti?fref=ts $>$ Acesso em: 01 jul. 2013).

Em (2), evocamos inicialmente of frame DESENHO ANIMADO DA DISNEY, cujos elementos constitutivos são os personagens TIMÃO e PUMBA do filme "O Rei Leão", que posteriormente ganharam papel principal no desenho "Timão e Pumba" também produzido pela Disney.
} 
Com base na relação entre esses personagens no próprio desenho, temos situações recorrentes de interação, que por serem previsíveis nos possibilitam o seguinte script: (i) Timão e Pumba vivem em situações de aventura e atrito; (ii) Na tomada de decisões, Timão quer ser sempre o líder; (iii) Pumba a princípio discorda; (iv) Timão faz chantagem e fica indiferente, mas no fundo sofre com a situação, embora não demonstre; (v) Pumba, caracterizado como o sentimental da relação, acaba cedendo para manter a amizade; (vi) Timão sempre tem razão e o que prevalece é a sua opinião.

Contextualizando as experiências e relação entre os personagens, destacamos que Timão (que é um suricate) adora tomar para si o mérito das ideias e de todo o serviço que o Pumba (javali africano) faça, enquanto que este é amável, extremamente protetor com seus amigos e odeia ser chamado de porco, prefere Sr. Porco. Pumba muitas vezes é inseguro e ingênuo, já que quase sempre não percebe (ou finge não perceber) que seu amigo Timão tira vantagem dele, ainda que, às vezes, tenha ideias geniais e planos muito inteligentes. ${ }^{6}$

Nesse sentido, podemos dizer que Pumba sempre acaba perdendo em seus argumentos, enquanto que Timão é sempre o líder. Os conceitos PERDEDOR e VENCEDOR, abstraídos do script de interação entre os personagens, são pontos cruciais para a comicidade da postagem analisada. Isso porque o autor utiliza essas características dos personagens do desenho e as atribui, respectivamente, aos referentes "Palmeiras" e "Corinthians", não homologados na superfície textual, mas passíveis de recuperação pela ancoragem em modelos cognitivos. Assim, temos a recategorização metafórica desses referentes como "Timão" e "Pumba", respectivamente.

O primeiro processo de recategorização se dá de forma mais explícita, uma vez que é comum entre os amantes ou acompanhantes de assuntos futebolísticos se referirem ao time Corinthians como Timão, porém, no contexto em análise, antes de remeter diretamente ao time essa expressão remete ao personagem do desenho animado da Disney, como se deixa explicitar no próprio cotexto.

$\mathrm{Na}$ subjacência dessas recategorizações, podemos derivar ainda o modelo cognitivo metafórico FUTEBOL É UMA COMPETIÇÃO, compreendendo-se que a comicidade da postagem 
decorre justamente da inversão do padrão, uma vez que o advérbio de negação não enfatiza a relutância do enunciador em acreditar que o time considerado perdedor tenha ganhado do Corinthians, ou seja, Pumba venceu Timão.

A expressão "Pumba", por sua vez, tradicionalmente remete ao parceiro de uma das duplas mais famosas dos desenhos infantis, entretanto, na publicação em questão, reiteramos, funciona como expressão referencial recategorizadora do referente "Palmeiras". Essa construção do referente ocorre por projeção metonímica/metafórica, uma vez que o mascote do time Palmeiras não oficial, porém, bastante difundido (senão o mais) é o porco ${ }^{7}$. Assim a reconstrução do referente "Palmeiras" só é possível a partir do conhecimento compartilhado dos interlocutores sobre a história de criação do mascote não oficial do time, já que desde sua invenção existe rivalidade entre os times aqui mencionados. ${ }^{8}$

A partir da análise empreendida na postagem 2, evidenciamos mais um caso de recategorização em que a (re)construção dos referentes "Palmeiras" e "Corinthians" extrapola o nível textual-discursivo, sendo estes referentes homologados no nível das estruturas e do funcionamento cognitivo, como postula Lima (2009).

Adiante, analisamos outra publicação do perfil fake de Irmã Zuleide, que remete ao tema religião, frequentemente abordado nesse perfil. Isso porque o autor se identifica como uma mulher crente da Igreja Universal e de forma humorística constrói sua imagem espelhando-se em fiéis evangélicos, com o propósito mais geral de ironizar os comportamentos e práticas dos adeptos e pastores dessa Igreja.

Figura 3 - POSTAGEM 3

Immã Zuleide $\cdot 3.075,402$ curtiram isso

3 ide Junho às 21:05.

Sempre vai existir aquela parte de uma música qualquer que vai te lembrar exatamente daquele exú que vc quer esquecer. Oremos

Curtir - Comentar - Compartilhar

26.047 pessoas curtiram isso.

Principais comentários -

Fonte: Captura em Print Screen. Disponível em: $<$ ttps://www.facebook.com/ZuleideJequiti?fref=ts > Acesso em: 01 jul. 2013. 
Na postagem (3), podemos evocar dois frames: RECORDAÇÃO AMOROSA e RELIGIÃO. Do primeiro, inferimos os seguintes elementos: RELAÇÃO AMOROSA, FINAL DE RELAÇÃO, EXPARCEIRO, dentre os quais destacamos EX-PARCEIRO, pois constitui um dos domínios relacionados às projeções metafóricas nessa postagem. Do segundo frame (RELIGIÃO), depreendemos os seguintes elementos: $\mathrm{EXU}^{9}$ ou ĖSÚ, que representa uma entidade ou orixá da religião candomblé, contemplado de forma negativa na publicação, e ADEPTO DA RELIGIÃO EVANGÉLICA.

Desse modo, na referida postagem são colocadas em conflito duas religiões, a evangélica e o candomblé. É justamente neste contexto de intolerância religiosa que se cria a comicidade na publicação, pois o enunciador refere-se no texto a uma das entidades mais importantes, na religião do candomblé, e em acepção pejorativa como sinônimo de satanás ou tentação, algo maléfico. É nessa acepção negativa que o referente "ex-parceiro" é recategorizado metaforicamente na postagem como "Exu". Na subjacência dessa recategorização, identificamos o modelo metafórico PESSOAS SÃO ENTIDADES MALIGNAS.

Fato curioso também é a própria semelhança sonora inicial entre as palavras Exu e Ex-parceiro, o que também pode constituir uma pista linguística. Contudo, uma explicação mais pertinente sobre a construção do referente "ex-parceiro" só se dá no plano cognitivo, uma vez que este não é homologado na superfície textual por uma expressão linguística, mas (re) construído pela ancoragem em modelos cognitivos.

\section{CONSIDERaÇões Finais}

Mediante as análises aqui apresentadas, apesar da restrição da amostra, pudemos confirmar a hipótese defendida em Lima (2009) da existência de referentes não homologados na superfície do texto e que por isso requerem para sua (re) construção a recorrência a mecanismos inferenciais, ancorados no nível das estruturas e do funcionamento cognitivo, porém, sempre guiados pelas pistas linguísticas.

Nesse universo, constatamos também a necessidade de um modelo de interface entre a Linguística de Texto e a Linguística Cognitiva, a exemplo da proposta de Lima e Feltes (2013), para uma 
descrição produtiva desse tipo de homologação de referentes, indiciado a partir de expressões referenciais recategorizadoras e ancorado nos MCIs (frame, script, metafórico e metonímico). Temos ciência de que as descrições feitas por meio da aplicação do referido modelo analítico, por se tratarem de apreensões de sentidos, embora sinalizadas pelas pistas linguísticas, não se esgotam e nem devem ser tomadas como únicas. Entretanto, podem ser elucidativas em termos de uma maior compreensão de mecanismos linguísticos complexos que não se revelam totalmente na materialidade do texto, a exemplo da construção dos referentes tematizados e recategorizados nas postagens analisadas neste trabalho.

Ressaltamos que o exercício de análise aqui empreendido pode ser visto como um desdobramento da Teoria dos Modelos Cognitivos Idealizados, no que concerne à aplicação desse modelo teórico a situações de uso cotidiano da linguagem, revelando a sua produtividade para a descrição da construção dos sentidos do texto em mais um contexto discursivo, ou seja, as postagens do perfil fake Irmã Zuleide.

The (Re)construction of References in a Fake Facebook Profile: A Cognitive Discourse Analysis

\section{ABSTRACT}

From a cognitive-discourse conception of the recategorization process, this paper analyzes the construction of referential recategorization expressions selected from three postings of the fake profile Irmã Zuleide. We took as an analysis model the Lima's e Feltes' (2013) proposal, which is based on the Theory of Idealized Cognitive Models (LAKOFF, 1987). The analysis encompasses the identification and description of cognitive models evoked from the materialized linguistic clues. The outputs confirm Lima's (2009) thesis that in the discourse some references can only be ratified if we call upon on the level of structures and cognitive functioning, requiring, therefore, anchorage in cognitive models.

Keywords: Referentiation, Recategorization, Idealized Cognitive Models, Facebook. 
LA (RE)CONSTRUCCIÓN DE REFERENTES EN EL PERFIL FAKE DEL FACEBOOK: UN ANÁLISIS COGNITIVO-DISCURSIVO

\section{RESUMEN}

A partir de una concepción cognitiva-discursiva del proceso de recategorización, este artículo analiza expresiones referenciales recategorizadas de tres publicaciones del perfil fake Irmã Zuleide. Tomamos como modelo de análisis la propuesta de Lima y Feltes (2013), que está basada en la Teoría de los Modelos Cognitivos Idealizados (LAKOFF, 1987). El análisis engloba la identificación y descripción de los modelos cognitivos evocados a partir de signos lingüísticos. Los resultados afirman la tesis de Lima (2009) de que, en la actividad discursiva, algunos referentes solo pueden ser homologados si recorremos al nivel de las estructuras y del funcionamiento cognitivo, necesitando, por lo tanto, de ancoraje en modelos cognitivos.

Palabras Claves: Referenciación, Recategorización, Modelos Cognitivos Idealizados, Facebook.

\section{Notas}

1 Fake é uma palavra da língua inglesa que significa falso ou falsificação. Com o advento das redes sociais designa uma conta na internet ou o perfil de alguém que pretende ocultar a verdadeira identidade (Disponível em: $<$ http:// www.significados.com.br/fake/ > . Acesso em: 01 jul. 2013).

2 Conforme Koch e Cunha-Lima (2004, p. 295), “ao invés de adotarem essa visão da referência como uma propriedade das palavras, como um fato imanente à língua, os autores sociocognitivistas preferem falar de referenciação, para realçar seu aspecto dinâmico, como uma atividade, um processo no qual os falantes se engajam para construir a referência”.

3 Ferrari (2011, p. 14) descreve a Linguística Cognitiva como uma nova vertente de estudos linguísticos estabelecidos mais apropriadamente nos anos 1980, em defesa de que "a relação entre palavra e mundo é mediada pela cognição. Assim, o significado deixa de ser reflexo direto do mundo e passa a ser visto como uma construção cognitiva através da qual o mundo é apreendido e experienciado". 
4 Feltes (2007, p. 88) explica, com base em Lakoff (1988), que "a cognição experiencialista toma o termo 'experiencial' em um sentido amplo, incluindo experiências sensório-motoras, emocionais, sociais, assim como capacidades inatas que dão forma a tais experiências e as tornam possíveis".

5 Os frames têm suas bases na Semântica dos Frames desenvolvida por Charles Fillmore (1976, 1977, 1982, 1985).

6 Para maiores informações, consultar: < http://garotasgeeks.com/ wordpress/2011/05/30/personagem-da-semana-timao-e-pumba/> Acesso em: 12 jul. 2013.

7 A história do porco como mascote tem sua origem na década de 60, motivada por uma série de insatisfações dos torcedores do Corinthians com a perseguição do Time do Palmeiras, tal chateação chegou ao estopim quando no ano de 1969 o Corinthians perdeu dois jogadores em um acidente de carro e teve seu pedido de substituição dos jogadores recusado, em virtude de um voto contra do presidente do Palmeiras na época, Delfino Facchina. Em consequência disso, a torcida do Corinthians resolveu provocar os palmeirenses e no clássico seguinte entre os times um dos torcedores soltou um porco no gramado com a camisa do Palmeiras, enquanto os alvinegros entoavam em coro: "Porcoooo!", provocando os rivais, isso de provocação passou a adoção do animal como mascote não oficial. Saber mais em: $<$ http:// www.tvbicho.com.br/variedades/o-mascote-oficial-do-palmeiras/7/444/>; $<$ http://www.meutimao.com.br /historia-do-corinthians/fatos-marcantes/a origem_do_apelido_da_porcada $>$. Acesso em: 12 jul. 2013.

8 Para outras informações, consultar: <http://pt.shvoong.com/ social-sciences/1623783-palmeiras-origem-porco-comomascote/\#ixzz2ZtbWvfcv>. Acesso em: 12 jul. 2013

9 "Para os nagôs dos candomblés tradicionais da Bahia, Èsù ou Exu - escrito na sua forma abrasileirada - é a principal entidade, não só do culto aos Orixás em que ele é a força dinâmica que move o sistema mítico ancestral, como também na vida, no dia-a-dia que, segundo a crença do povo de santo, é a energia que vitaliza as pessoas e de tudo o que existe. Em resumo, sem Exu não tem movimento, logo sem ele não teríamos culto aos orixás, nem vida para os seres" (SOARES, 2008, p. 37). 


\section{REFERÊNCIAS}

APOTHÉLOZ, D.; REICHLER-BEGUELIN, M. J. Construction de la reference et stratégies de désignation. IN: BERRENDONNER, A; REICHLER-BÉGUELIN, M. J. (Ed.) Du sintagme nominal aux objects-dediscours: SN complexes, nominalizations, anaphores. Neuchâtel: Institute de Linguistique de l'Université de Neuchâtel, 1995. P. 227-271.

CAVALCANTE, M. M.; CUSTÓDIO FILHO, V. Revisitando o estatuto do texto. Revista do GELNE, Piauí, v. 12, n. 2, 2010, p. 56-71.

CAVALCANTE, M. M. Referenciação: sobre coisas ditas e não ditas. Fortaleza: Edições UFC, 2011.

CUSTÓDIO FILHO, V. Múltiplos fatores, distintas interações: esmiuçando o caráter heterogêneo da referenciação, 2011. 330f. Tese (Doutorado em Linguística). Centro de Humanidades, Universidade Federal do Ceará, Fortaleza, 2011.

. Reflexões sobre a recategorização referencial sem menção anafórica. Ling. (dis) curso [online]. Tubarão, vol.12, n.3, dez. 2012. pp. 839-859. ISSN 1518-7632. Disponível em: <http://www.scielo.br/scielo.php?pid=S151876322012000300009\&script=sci_arttext $>$. Acesso em: 10 jul. 2013.

FELTES, H. P. M. Semântica cognitiva: ilhas, pontes e teias. Porto Alegre: Edipucrs, 2007.

FERRARI, L. Introdução à Linguística Cognitiva. São Paulo: Contexto, 2011.

FILLMORE, C. J. Frame semantics and the nature of language. Annais of the New York Academy of Science: Conference on the origin and development of language and speech, v. 280, p. 2032, 1976.

. The need for a frame semantics in linguistics. In: KARLGREN, H. (Ed.). Statistical Methods in Linguistics, n. 12, p. 5-29, 1977.

. Towards a descriptive framework for especial deixis. In: JARVELLA, R. J.; KLEINS, W. (Ed.). Speech, place, and action. London: John Wiley, 1982a, p. 31-59.

. Frame semantics. In: Linguistic Society of Korea (Ed.). Linguistics in the morning calm. Seoul: Hanshin, 1982b.

. Frames and semantics of understanding. Quaderni di Semantica. v.6, n.2, 222-255, 1985. 
KOCH, I. G. V.; CUNHA-LIMA, M. L. Do cognitivismo ao sociocognitivismo. In: MUSSALIM, F.; BENTES, A.C. (Org.). Introdução à Linguística: fundamentos epistemológicos. Vol. 3. São Paulo: Cortez, 2004.

KOCH, I. G. V. Desvendando os segredos do texto. São Paulo: Cortez, 2011. LAKOFF, G.; JOHNSON, M. Metaphors we live by. Chicago: University of Chicago Press, 1980.

. Philosophy in the flesh: the embodied mind and its challenge to western thought. New York: Basic Books, 1999.

LAKOFF, G. Women, fire and dangerous things: what categories reveal about the mind. Chicago: University of Chicago Press, 1987.

.Cognitive Semantics. In: ECO, U; SANTAMBROGIO, M.; VIOLI, P. (Ed.). Meaning and mental representations. Indianapolis: Indiana University Press, 1988, p. 119-154.

. The contemporary theory of metaphor. In: Ortony, Andrew (Ed.). Metaphor and thought. 2 ed. Cambridge, U.K.: Cambridge University Press, 1993, p. 202-251.

LIMA, S. M. C. Entre os domínios da metáfora e metonímia: um estudo de processos de recategorização. Tese (Doutorado em Linguística). Centro de Humanidades, Universidade Federal do Ceará, Fortaleza, 2009. 204 p.

; FELTES, H. P. M..A construção de referentes no texto/discurso: um processo de múltiplas âncoras. In: CAVALCANTE, M. M.; LIMA, S. M. C. (Org.). Referenciação: teoria e prática. São Paulo: Cortez, 2013.

MONDADA, Lorenza; DUBOIS, Danièle. Construction des objets de discours et catégorisation: une approche des processus de reférentiation. TRANEL (Travaux Neuchâtelois de Linguistique), n. 23, p. 273-302, 1995.

Construção dos objetos de discurso e categorização: Uma abordagem dos processos de referenciação. In: CAVALCANTE, M. M.; BIASI-RODRIGUES, B.; CIULLA, A. Referenciação. São Paulo: Contexto, 2003. (Coleção Clássicos de Linguística).

SCHANK, R. C.; KASS, A. Knowledge representation in people and machines. In: ECO, U.; SANTAMBROGIO, M.; VIOLI, P. (Ed.). Meaning and mental representations. Indianópolis: Indiana University Press, 1988. P. 181-200.

SOARES, E. L. R. As vinte e uma faces de Exu na filosofia afrodescendente da educação [manuscrito]: imagens, discursos e narrativas. Tese (Doutorado em Educação). Universidade Federal do Ceará, Faculdade de Educação, 
Programa de Pós-Graduação em Educação, Fortaleza (CE), 2008. Disponível em: $\quad<$ http://www.teses.ufc.br/tde_busca/arquivo.php?codArquivo=1805>. Acesso em: 12 jul. 2013.

Submetido em 1 de julho de 2014

Aceito em 27 de maio de 2015

Publicado em 21 de dezembro de 2015

394 Oliveira, A. V. A.; Lima, S. M. C. A (RE)Construção de Referentes em Perfil... 